\title{
Utilization of Parked EV-ESS for Power Management in a Grid-Tied Hybrid AC/DC Microgrid
}

\author{
Md Shamiur Rahman, Student Member, IEEE, M. J. Hossain, Senior Member, IEEE, \\ and Junwei Lu, Senior Member, IEEE
}

\begin{abstract}
This paper proposes an electric vehicle-energy storage system (EV-ESS) charge/discharge controller based on the deviation between load power and generated power. An interlinking converter is designed which acts as a gateway between $\mathrm{AC}$ and DC subgrids of the grid-tied hybrid AC/DC microgrid system. It has the ability to control both active and reactive power based on individual control mechanisms. To control the reactive power in the system a reactive power controller is proposed and designed within the interlinking converter controller. The reactive power controller operates based on the manipulation of point of common coupling (PCC) reactive power and RMS voltage with their associated references. A generalized grid-tied hybrid AC/DC microgrid is designed with a PV module and a doubly fed induction generator (DFIG) wind turbine mimicking the real life microgrid model in Griffith University, Nathan campus. The simulation is carried out in MATLAB/SIMULINK environment to prove the effectiveness of both controllers. Simulation results show that both reactive power controller and EV-ESS charge/discharge controller perform efficiently under variable loading and variable irradiation conditions which facilitate smooth vehicle to grid (V2G)/vehicle to microgrid (V2M) operation.
\end{abstract}

Index Terms-Hybrid AC/DC microgrid, DFIG wind turbine, PV module, EV-ESS, V2G/V2M, active and reactive power control and management.

\section{INTRODUCTION}

D EPLOYMENT of distributed renewable energy resources (DRER) is increasing due to recent global concern about fuel price hiking and environmental pollution caused by conventional power sources. As a result, microgrid - a building block of future smart grid vision, is now an extensively accepted concept because of its flexible and bidirectional power flow strategy and superior connectivity with alternative sources and utility grids. As the most of the renewable energy sources have DC output power and because of increasing DC load demand the concept of DC microgrid has recently been emerged with lots of potentials. Nevertheless, DC microgrids are not expected to be deployed solely in near future. It is due to the fact that majority of utility grids are still operating on AC system and three phase AC system is prevailing for more than hundred years. On the other hand to supply AC loads DC sources are needed to be converted into AC. As a result, $\mathrm{AC}$ microgrid is more common. However, again an $\mathrm{AC}$ microgrid needs conversion from $\mathrm{AC}$ to $\mathrm{DC}$ for supplying

Md Shamiur Rahman, M. J. Hossain and Junwei Lu are with Griffith School of Engineering, Griffith University, Gold Coast, QLD - 4222, Australia (e-mail: mdshamiur.rahman@griffithuni.edu.au, j.hossain@griffith.edu.au, j.lu@griffith.edu.au).
DC loads. These multiple AC/DC/AC conversions through nonlinear power electronics based converters reduce overall efficiency and at the same time make the system complex and vulnerable. As a result the concept of hybrid AC/DC microgrid has been proposed in literatures. The concept of hybrid AC/DC microgrid system is to combine both AC and DC renewable/non-renewable power sources along with corresponding $\mathrm{AC}$ and $\mathrm{DC}$ loads. A hybrid AC/DC microgrid is composed of individual $\mathrm{AC}$ and $\mathrm{DC}$ bus. At the point of $\mathrm{AC}$ bus, AC sources like wind turbines and utility grids along with AC loads like induction motors are connected. DC sources like PV, fuel cells, electric vehicle - energy storage systems (EVESS) etc. and loads like data centres, telecommunication base stations etc. are connected at DC bus point. The AC and DC bus are interfaced with an interlinking converter which acts as a gateway for the power flow between AC and DC subgrids [1], [2].

The usage of EVs and plug-in hybrid EVs (PHEVs) are increasing rapidly because of recent advancements in their energy storage systems. One of the most fascinating things about these vehicles is their dual dynamic characteristics as a load while in G2V (grid to vehicle) mode and as a generator while in V2G (vehicle to grid) mode. With proper utilization of EV-ESS, V2G concept can improve the utility grid's performance in the area of efficiency, stability and reliability by offering reactive power management, active power control, tracking the intermittent renewable energy resources, load balancing and shifting via valley filling support, peak load shaving and filtering current harmonics in the output. But to extract optimum performance from EV-ESS proper charging discharging controller needs to be designed. Sophisticated active and reactive power regulation as well as state-of-the-art monitoring system is required to overcome the impacts and to implement successful interfacing. EV-ESS can significantly contribute in enhancing dynamic performance and stability of the microgrid under different operating and loading conditions if they can be implemented in a coordinated and controlled manner [3].

Utilization and impact of EV-ESS considering conventional microgrid structure is well explored for active power balancing or for frequency regulation [4]-[6]. But extracting these facilities of EV-ESS for hybrid multi bus microgrid structure requires further attention. Considering the fact this paper proposes an EV-ESS charge/discharge controller where EVESS is modelled and recalibrated using Mitsubishi Outlander 


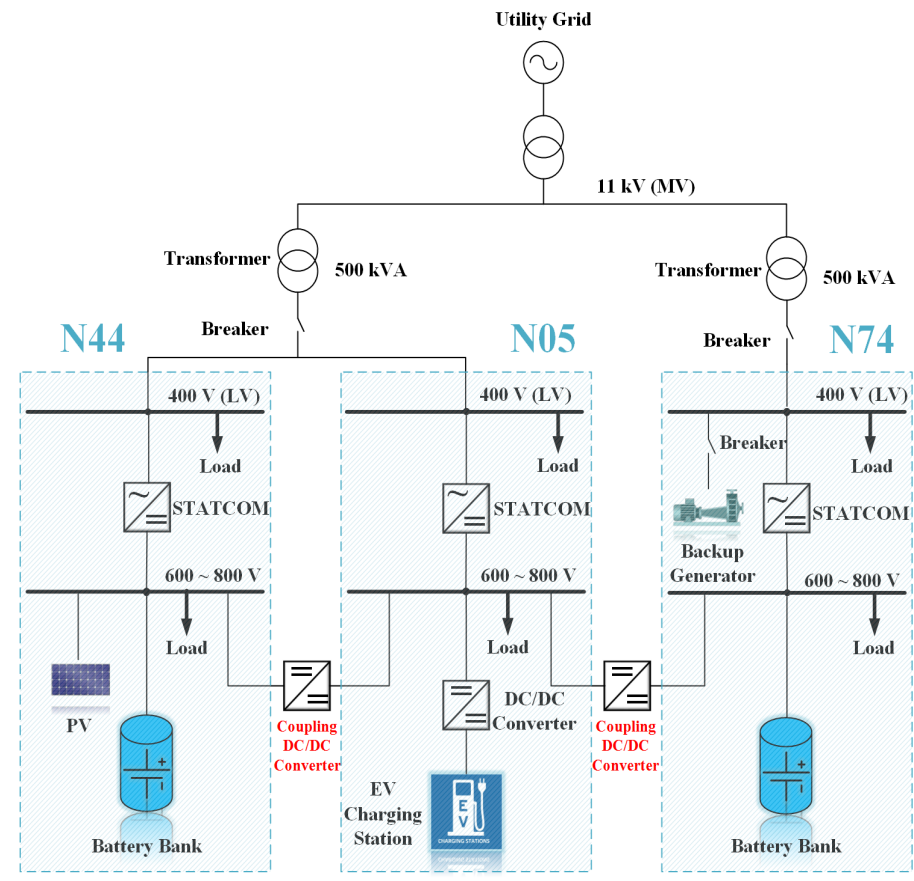

(a) Hybrid AC/DC microgrid in Griffith University, Nathan campus
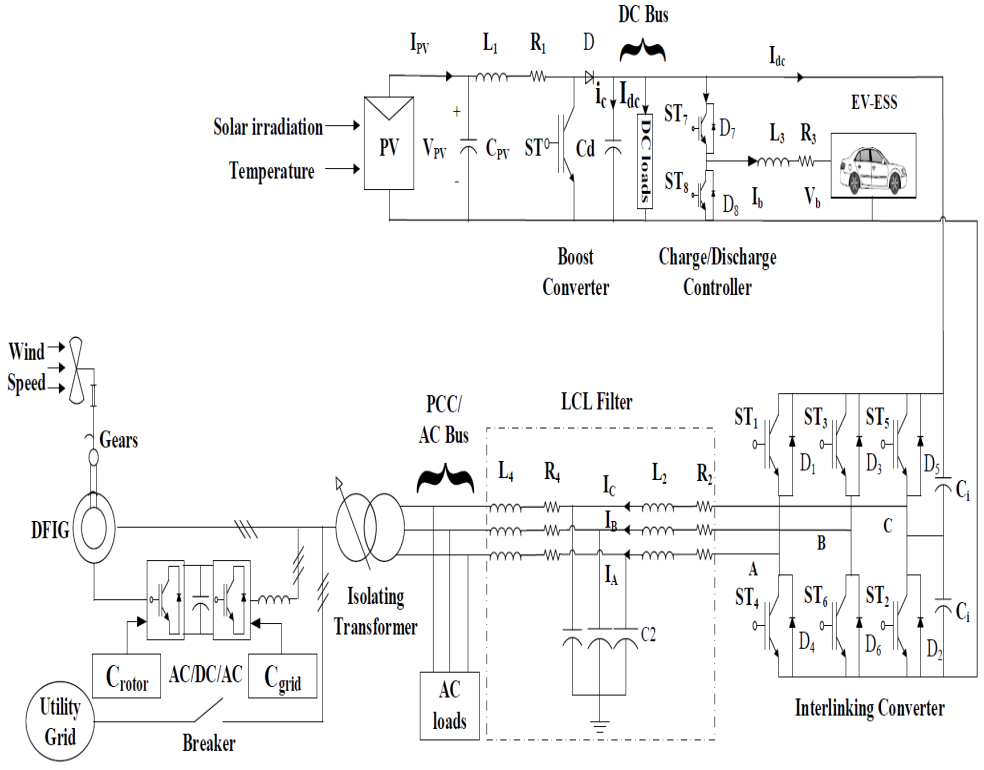

(b) Simulation model of the hybrid AC/DC microgrid

Fig. 1: Hybrid AC/DC microgrid model

plug-in hybrid electric vehicle (PHEV) specification [7]. The EV-ESS controller takes measured total generated power and compares it with measured total load requirement and based on state-of-charge (SOC) status of parked EV-ESS supply or consumes active power accordingly to mitigate active power deviation. Reactive power control in a hybrid AC/DC microgrid via interlinking converter has been discussed in some recent literatures. Usually reactive power control is achieved by comparing measured AC bus RMS voltage, reactive power or power factor with their corresponding reference values [8]. In [1] and [9] point of common coupling (PCC) reactive power is compared with load reactive power requirement and in [10] comparison of quadrature components of load and PCC current is used to generate reference for reactive power control. A $V-Q$ droop based reactive power control has been utilized in [2] and [11]-[13]. Reactive power compensation based on the strategy of instantaneous power-based current control has been proposed in [14]. The reference value can be obtained by only comparing the PCC reactive power with the required load reactive power. This method provides better reactive power management but hampers PCC voltage regulation and increase harmonics. Comparison of PCC voltage with its reference can also serve the purpose which is actually a preferable method when PCC voltage regulation is of prime concern. Adopting these conventional methods will result in increasing harmonics and distorted power quality. To overcome these shortcomings in this paper a combination of both existing methods have been adopted to develop a novel reactive power controller which can eliminate these shortcomings. The reactive power controller performs two stage comparisons. In the first stage PCC reactive power is compared with load reactive power requirement. In second stage the difference is further compared with the controlled deviation of PCC RMS voltage with its corresponding reference. The output is then fed as reactive power control input. Both EV-ESS charge/discharge controller and reactive power controller is utilized in a simulated hybrid AC/DC microgrid which is developed mimicking the real microgrid in Griffith University, Nathan campus to prove controllers' superior performance under variable loading and variable irradiation. The remainder of the paper is organized as follows. Section II introduces the designed hybrid AC/DC microgrid. Section III discusses about control strategies. Time domain simulations to verify the performance of the controllers under variable irradiation and variable loading are presented in Section IV and a concluding remark is presented in Section V.

\section{HYBRID AC/DC MICROGRID SYSTEM}

The configuration of the grid-tied hybrid AC/DC microgrid is shown in Fig. 1 where the first schematic shows the real microgrid in Griffith University, Nathan campus and former one shows the simulation model inspired by the real model. The real microgrid structure consists of three buildings namely N44, N05 and N74 of Griffith University, Nathan campus. Each building has individual AC and DC buses and corresponding loads connected to them. Both buses are interfaced with bi-directional static synchronous compensator (STATCOM) as interlinking converter. N44 building contains a $10 \mathrm{~kW} \mathrm{PV} \mathrm{module} \mathrm{with} \mathrm{battery} \mathrm{energy} \mathrm{storage} \mathrm{for} \mathrm{peak}$ demand management. An EV charging station with DC/DC converter is planned to be installed in N05 building. N74 building contains sensitive loads attached to both buses which are served by backup diesel generator and battery energy storage during outage. Each DC bus is planned to be interfaced 
Interlinking Converter Controller

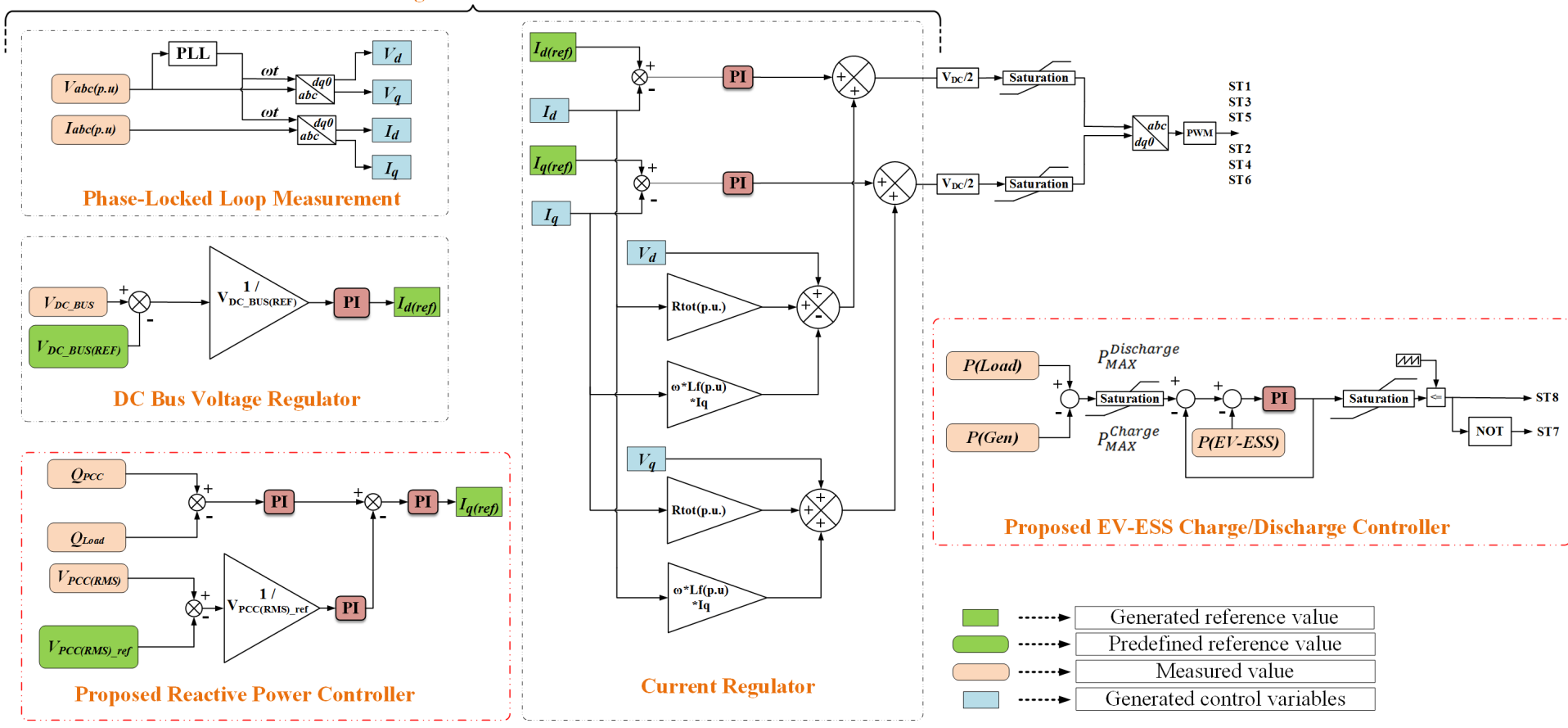

Fig. 2: Overall control strategies

with its neighbouring DC bus via coupling DC/DC converters. A simulation model of the microgrid has been designed in MATLAB/SIMULINK environment mimicking the real structure which contains single pair of AC and DC buses.

The simulation model is composed of two portions -a DC subgrid and an AC subgrid. The DC subgrid consists of a PV module of $40 \mathrm{~kW}$ with maximum power point tracking (MPPT) system integrated boost converter and two parallel EV-ESSs with a bidirectional IGBT based buck-boost converter. MATLAB/SIMULINK software library provides standard Li-Ion battery model which is used here. Batteries have been recalibrated according to the specification of Mitsubishi Outlander PHEV battery model [7] to get realistic results. Both PV system and EV-ESS are connected to the DC bus. The AC subgrid consists of a $50 \mathrm{~kW}$ doubly-fed induction generator (DFIG) wind turbine farm and a utility grid which are connected to the $\mathrm{AC}$ bus through an isolating transformer. The nominal DC bus is $600 \mathrm{~V}$ and the nominal $\mathrm{AC}$ bus RMS voltage is $230 \mathrm{Vrms}$ (L-G). Both buses are connected via interlinking bidirectional converter which acts as both inverter and STATCOM. An LCL filter has been used between PCC and interlinking converter to smoothen converter output voltage wave shape. All the parameters of the simulation model are given in Appendix-A.

\section{CONTROL STRATEGY}

The designed hybrid AC/DC microgrid includes two types of controller proposed as interlinking voltage source controller and EV-ESS charge/discharge controller. Overall control strategies are depicted in Fig. 2. In this section a brief overview of the structures and strategies of these controllers are presented.

\section{A. Interlinking converter controller}

The interlinking converter consists of four interconnected subsystems.

1) Phase-locked loop (PLL) measurement: Measured grid side voltage $\left(V_{a b c}\right)$ is fed to a PLL to get instantaneous angle measurement which is later fed into $a b c / d q 0$ converter. Measured grid side voltage $\left(V_{a b c}\right)$ and current $\left(I_{a b c}\right)$ are passed through $a b c / d q 0$ converter to get corresponding $d$ and $q$ axis components i.e. $V_{d}, V_{q}, I_{d}$ and $I_{q}$.

2) DC Bus voltage regulator: The objective of this subsystem is to regulate DC bus voltage and to generate reference value for the active power control input i.e, $I_{d(r e f)}$. In order to do so measured DC voltage is compared with its reference voltage (i.e. $600 \mathrm{~V}$ ) and then passed through a proportionalintegral (PI) controller to generate control input $I_{d(r e f)}$.

3) Proposed reactive power controller: Active and reactive power of a non-inertial system can be controlled by $I_{d}$ and $I_{q}$ respectively [15]. The main task of the proposed reactive power controller is to generate reference value for $I_{q}$ which is $I_{q(r e f)}$. The controller compares PCC reactive power $\left(Q_{P C C}\right)$ with required load reactive power $\left(Q_{\text {Load }}\right)$ and the result is passed through a PI controller. PCC RMS voltage is also compared with its reference value which in this case in 230 Vrms and the result is passed through another PI controller. Both results are again compared and passed through another PI controller to generate $I_{q(r e f)}$.

4) Current regulator: The main task of the current regulator is to compare $I_{d}$ and $I_{q}$ with their associated references $I_{d(r e f)}$ and $I_{q(r e f)}$ and decouple active and reactive power control from each other. As a result, the controller performance becomes independent of system dynamics. 


\section{B. Proposed EV-ESS charge/discharge controller}

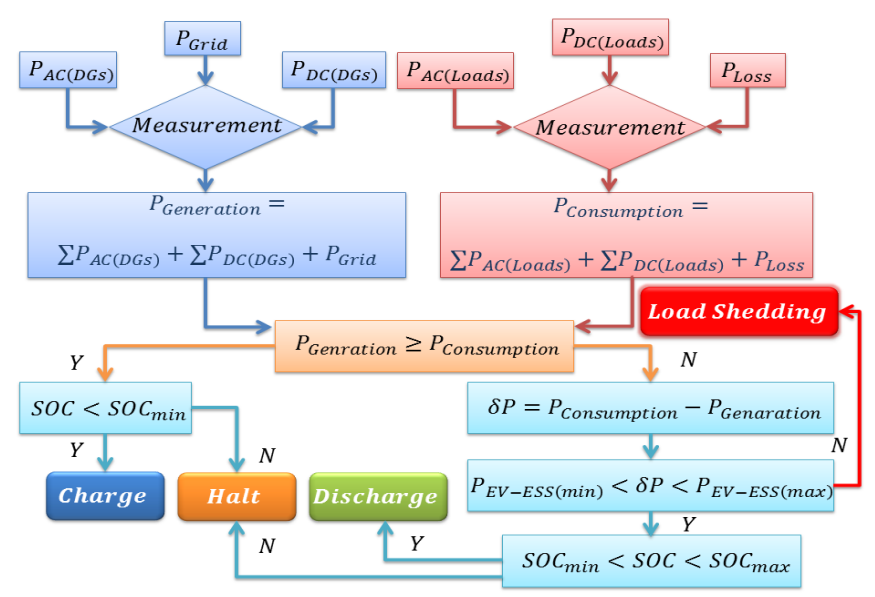

Fig. 3: Control algorithm for EV-ESS charge/discharge controller

In grid connected mode it is expected that grid will provide necessary load requirement at the same time it will contribute as the active and reactive power regulator [9]. But in case of overloading due to variable loading or variable irradiation effects, parked EV-ESS can contribute to line voltage regulation and power management. For the designed hybrid AC/DC microgrid, generation and load demand can be calculated as below

$$
P_{\text {Generation }}=\sum P_{A C(D G s)}+\sum P_{D C(D G s)}+P_{\text {grid }}
$$

Where $P_{\text {grid }}=$ power supplied by the grid,

$P_{D C(D G s)}=$ power generated by DC DGs $=P_{P V}=$ power supplied by PV either to load or to the grid,

$P_{A C(D G s)}=$ power generated by AC DGs $=P_{W T}=$ Power supplied by the DFIG WT either to load or to the grid, so overall load demand is

$$
\begin{aligned}
P_{\text {Consumption }} & =\sum P_{A C(\text { Loads })}+\sum P_{D C(\text { Loads })} \\
& +P_{\text {Loss }}
\end{aligned}
$$

In normal condition it is expected that

$$
P_{\text {Generation }} \geq P_{\text {Consumption }}
$$

During that time EV-ESS will be charged via buck/boost converter or maintain halt mode based on battery SOC requirement. But if there is any generation-consumption mismatch occurs at the PCC point then there might be condition when the following situation will occur

$$
P_{\text {Generation }}<P_{\text {Consumption }}
$$

For this case EV-ESS will measure the power difference $\delta P$ and compare $\delta P$ with maximum allowable power range of EVESS battery packs. If the $\delta P$ is in the allowable range then the controller will check battery SOC and based on SOC status control signals will be generated either to discharge battery power or to maintain halt condition. If $\delta P$ is higher than the maximum allowable battery power then it will generate a load shedding command to maintain overall power balance in the system. The control algorithm for EV-ESS charge/discharge control is illustrated in Fig. 3. In a microgrid, energy storages are used primarily for bus voltage regulation and secondarily as an active power balancer. As a result conventionally DC bus voltage is taken as a reference which is further compared to battery current through PI controller [16]. The proposed EV-ESS controller only contributes to active power balancing thus it features plug and play service.

\section{CASE STUDIES}

The objective of this section is to carry out time domain simulation in MATLAB/SIMULINK environment to verify the effectiveness of the controllers under variable irradiation and variable loading conditions. Simulation is carried out for 3.5 seconds considering the microgrid is connected with a $50 \mathrm{~Hz}$ utility grid.

\section{A. Variable irradiation}

The system is exposed to variable irradiation ranging from $250 \mathrm{~W} / \mathrm{m}^{2}$ to $1200 \mathrm{~W} / \mathrm{m}^{2}$. Both $\mathrm{AC}$ and DC loads are kept constant as $30 \mathrm{~kW}+20 \mathrm{kVAR}$ and $20 \mathrm{~kW}$ respectively throughout the period. The effect of variable irradiation on system active and reactive power profile can be observed in Fig. 4 and Fig. 5 respectively. It can be concluded from results that active and reactive power are properly managed by EV-ESS controller and reactive power controller respectively during variable irradiation.

\section{B. Variable loading}

The system is exposed to variable AC and DC loads for the period of 3.5 seconds. The duration and values of $\mathrm{AC}$ and $\mathrm{DC}$ loads are given in Table I. Fig. 6 and Fig. 7 presents the active

Table - I

\begin{tabular}{|c|c|c|}
\hline Period (s) & DC Load $(\mathbf{k W})$ & AC Load $(\mathbf{k V A})$ \\
\hline $0.3-0.6$ & 10 & 10 \\
\hline $0.6-1$ & 20 & $30+j 20$ \\
\hline $1-1.5$ & 20 & $100+j 80$ \\
\hline $1.5-2.3$ & 20 & $50+j 10$ \\
\hline $2.3-3$ & 20 & $40+j 30$ \\
\hline $3-3.3$ & 20 & $5+j 5$ \\
\hline $3.3-3.5$ & 20 & 0 \\
\hline
\end{tabular}

and reactive power profile of the system under variable load condition. It can be observed that even under variable $\mathrm{AC}$ and DC loading condition EV-ESS can effectively meet load active power requirement and the proposed reactive power controller can meet load reactive power requirements. In Fig. 8 and Fig. $9 \mathrm{AC}$ and DC bus voltages and EV-ESS SOC are illustrated. It can be observed from Fig. 8 that the designed controller provides excellent performance in following reference voltages in terms of damping, overshoot, oscillation and settling time. Fig. 10 and Fig. 11 depict harmonic condition of PCC voltage and current. According to the IEEE-1547 series of standards, total harmonic distortion (THD) of PCC current and voltage should not exceed $5 \%$ of the fundamental frequency [17]. It can be observed from Fig. 10 and Fig. 11 that both PCC voltage (THD: 4.28\%) and current (THD: 4.39\%) of the designed microgrid is following that regulatory standards.

From the above results it can be concluded that proposed and designed reactive power controller and EV-ESS 


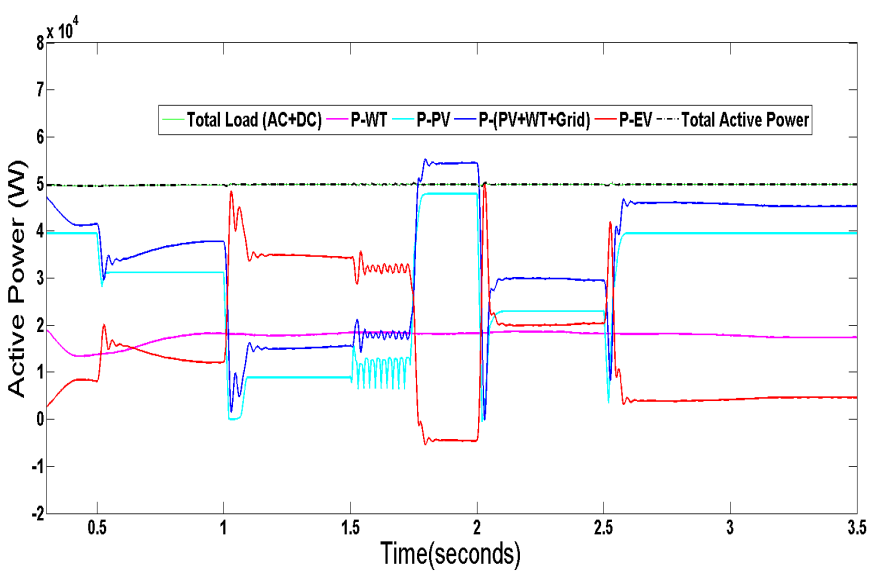

Fig. 4: System active power profile under variable irradiation

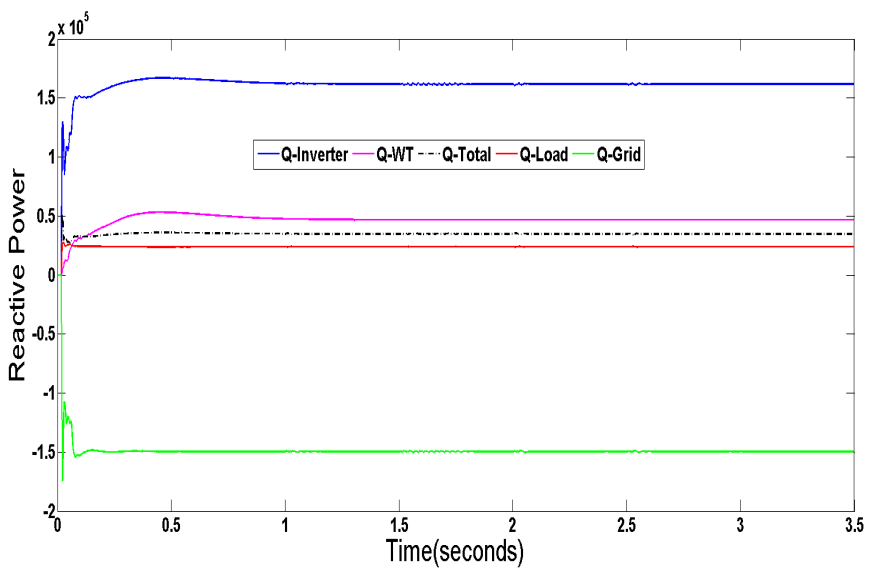

Fig. 5: System reactive power profile under variable irradiation

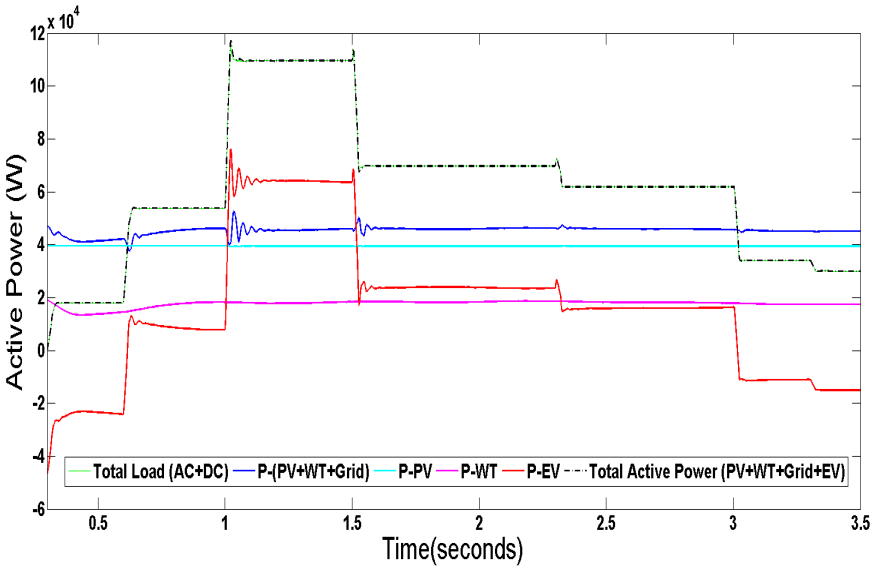

Fig. 6: System active power profile under variable loading

charge/discharge controller can effectively control reactive power and active power within the system. It can also be observed that the designed interlinking converter is capable of maintaining $\mathrm{AC}$ and $\mathrm{DC}$ bus voltage within acceptable region even under variable loading and variable irradiation conditions.

\section{Conclusion And Future Trend}

In this paper, a novel reactive power controller has been proposed which operates based on the manipulation of PCC reactive power and PCC RMS voltage with their associated

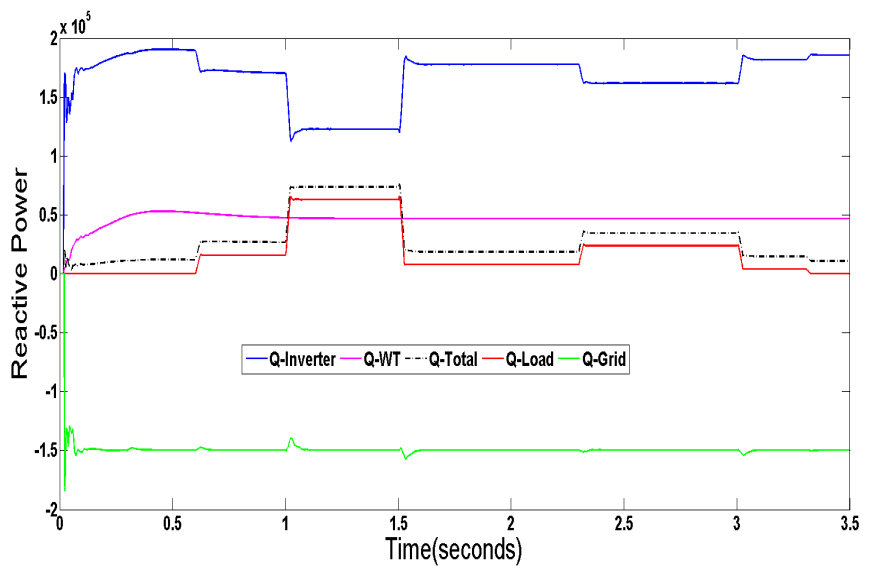

Fig. 7: System reactive power profile under variable loading

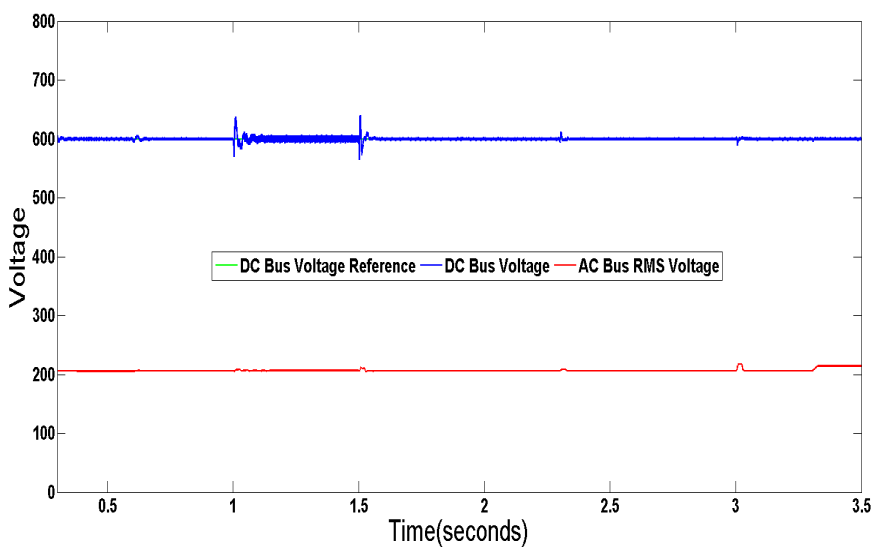

Fig. 8: DC bus voltage and AC bus RMS voltage under variable loading

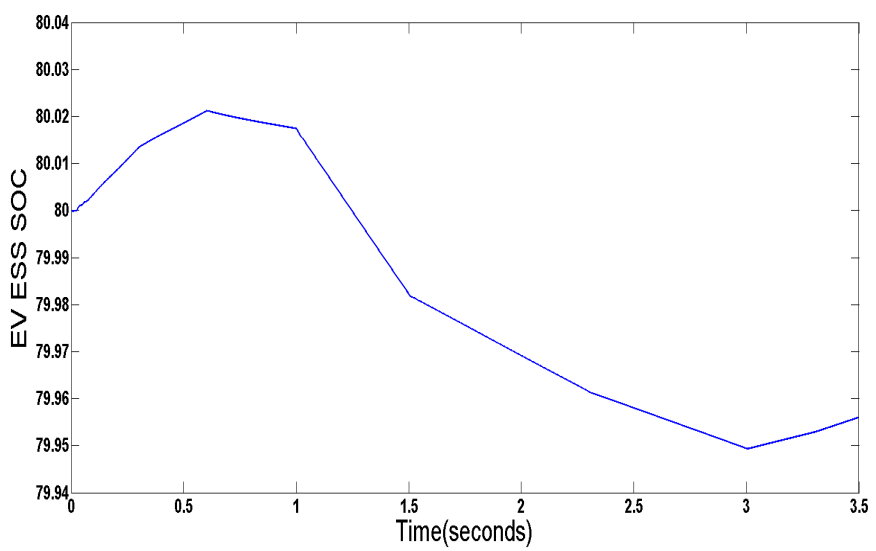

Fig. 9: EV-ESS SOC under variable loading

references. An EV-ESS charge/discharge controller has been proposed and designed to manage power flow between the $\mathrm{AC}$ and DC subgrids of a hybrid AC/DC microgrid. EVESS battery packs have been recalibrated based on Mitsubishi Outlander PHEV specification for accurate simulation result. Additionally, an interlinking controller is designed to stabilize voltages of corresponding buses and to maintain overall control of the system. Simulation results show that both reactive power controller and EV-ESS charge/discharge controller efficiently manage reactive and active power respectively within 


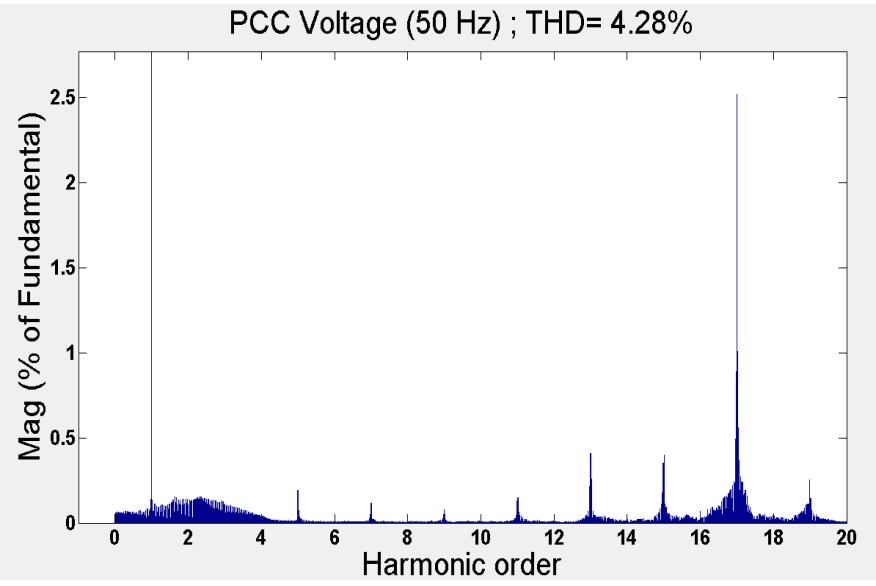

Fig. 10: PCC current total harmonic distortion (\%THD)

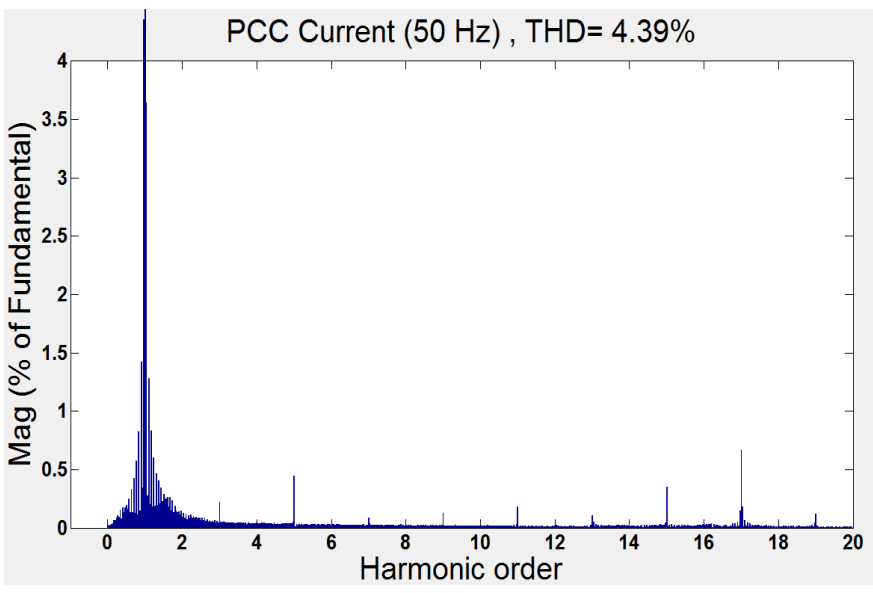

Fig. 11: PCC voltage total harmonic distortion (\%THD)

the designed system. The effects of wind gust on DFIG WT, uncertainty of PHEV charging pattern and multiple pair of DC and $\mathrm{AC}$ buses have not been considered in this paper, which can be identified as future scopes of this research.

\section{APPENDIX A}

\section{HYBRID AC/DC MICROGRID SIMULATION MODEL}

\begin{tabular}{|l|c|c|c|}
\hline \multicolumn{3}{|c|}{ Energy Nodes } \\
\hline PV Module & \multicolumn{2}{c|}{$40 \mathrm{~kW}$} \\
\hline DFIG wind turbine & \multicolumn{2}{|c|}{$50 \mathrm{~kW}$} \\
\hline Single EV-ESS battery pack & \multicolumn{2}{|c|}{$300 \mathrm{~V} / 40 \mathrm{Ah}$} \\
\hline \multicolumn{2}{|c|}{ Network Parameters } \\
\hline DC bus voltage & \multicolumn{3}{|c|}{$600 \mathrm{~V}$} \\
\hline AC bus RMS voltage & \multicolumn{2}{|c|}{$230 \mathrm{Vrms}$} \\
\hline$L_{1}$ & $5 m H$ & $R_{1}$ & $0.005 \Omega$ \\
\hline$L_{2}$ & $250 \mu H$ & $R_{2}$ & $2 m \Omega$ \\
\hline$L_{3}$ & $5 m H$ & $R_{3}$ & $1 \Omega$ \\
\hline$L_{4}$ & $250 \mu H$ & $R_{4}$ & $2 \Omega$ \\
\hline$C_{p v}$ & \multicolumn{3}{|c|}{$100 \mu F$} \\
\hline$C_{2}$ & \multicolumn{3}{|c|}{$100 \mu F$} \\
\hline$C_{i}$ & $1200 \mu F$ \\
\hline \multicolumn{2}{|c|}{ Controller Parameters } \\
\hline \multirow{2}{*}{ VSC Current Regulator } & $K_{p}$ & 0.3 \\
\cline { 2 - 4 } & $K_{i}$ & 20 \\
\hline \multirow{2}{*}{ VSC Voltage Regulator } & $K_{p}$ & 7 \\
\cline { 2 - 4 } & $K_{i}$ & 800 \\
\hline \multirow{2}{*}{ EV-ESS Controller } & $K_{p}$ & 7 \\
\cline { 2 - 4 } & $K_{i}$ & 800 \\
\hline \multicolumn{3}{|c}{} \\
\hline
\end{tabular}

\section{REFERENCES}

[1] X. Liu, P. Wang, and P. C. Loh, "A hybrid ac/dc microgrid and its coordination control," IEEE Transactions on Smart Grid, vol. 2, no. 2, pp. 278-286, Jun. 2011, ISSN: 1949-3053.

[2] P. C. Loh, D. Li, Y. K. Chai, and F. Blaabjerg, "Autonomous control of interlinking converter with energy storage in hybrid ac x2013; dc microgrid," IEEE Transactions on Industry Applications, vol. 49, no. 3, pp. 1374-1382, May 2013, ISSN: 0093-9994.

[3] M. Yilmaz and P. Krein, "Review of the impact of vehicle-to-grid technologies on distribution systems and utility interfaces," IEEE Transactions on Power Electronics, vol. 28, no. 12, pp. 5673-5689, Dec. 2013, ISSN: 0885-8993.

[4] S. Y. Derakhshandeh, A. S. Masoum, S. Deilami, M. A. S. Masoum, and M. E. Hamedani Golshan, "Coordination of Generation Scheduling with PEVs Charging in Industrial Microgrids," IEEE Transactions on Power Systems, vol. 28, no. 3, pp. 3451-3461, Aug. 2013, ISSN: 0885-8950.

[5] L. Jian, H. Xue, G. Xu, X. Zhu, D. Zhao, and Z. Y. Shao, "Regulated Charging of Plug-in Hybrid Electric Vehicles for Minimizing Load Variance in Household Smart Microgrid," IEEE Transactions on Industrial Electronics, vol. 60, no. 8, pp. 3218-3226, Aug. 2013, ISSN: 0278-0046.

[6] S. Beer, T. Gomez, D. Dallinger, I. Momber, C. Marnay, M. Stadler, and J. Lai, "An Economic Analysis of Used Electric Vehicle Batteries Integrated Into Commercial Building Microgrids," IEEE Transactions on Smart Grid, vol. 3, no. 1, pp. 517-525, Mar. 2012, ISSN: 19493053.

[7] Outlander PHEV Specifications - Mitsubishi Motors Australia. [Online]. Available: http://www. mitsubishi-motors.com.au/vehicles/ outlander-phev/specifications (visited on 03/31/2015).

[8] F. Katiraei and M. Iravani, "Power management strategies for a microgrid with multiple distributed generation units," IEEE Transactions on Power Systems, vol. 21, no. 4, pp. 1821-1831, Nov. 2006, ISSN: 0885-8950.

[9] N. Eghtedarpour and E. Farjah, "Power control and management in a hybrid ac/dc microgrid," IEEE Transactions on Smart Grid, vol. 5, no. 3, pp. 1494-1505, May 2014, ISSN: 1949-3053.

[10] F. H. M. Rafi, M. Hossain, and J. Lu, "Design of a single stage transformerless vsi in a smart microgrid for pv-statcom/ess operations," in Power Engineering Conference (AUPEC), 2014 Australasian Universities, IEEE, 2014, pp. 1-6.

[11] J. M. Guerrero, L. Poh Chiang, L. Tzung-Lin, and M. Chandorkar, "Advanced Control Architectures for Intelligent Microgrids - Part II: Power Quality, Energy Storage, and AC/DC Microgrids," IEEE Transactions on Industrial Electronics, vol. 60, no. 4, pp. 1263-1270, 2013, ISSN: 0278-0046.

[12] R. Majumder, "A Hybrid Microgrid With DC Connection at Back to Back Converters," IEEE Transactions on Smart Grid, vol. 5, no. 1, pp. 251-259, 2014

[13] X. Lu, J. M. Guerrero, K. Sun, J. C. Vasquez, R. Teodorescu, and L. Huang, "Hierarchical control of parallel AC-DC converter interfaces for hybrid microgrids," IEEE Transactions on Smart Grid, vol. 5, no. 2, pp. 683-692, 2014, ISSN: 19493053.

[14] P. Shanthi, U. Govindarajan, and D. Parvathyshankar, "Instantaneous power-based current control scheme for VAR compensation in hybrid AC/DC networks for smart grid applications," IET Power Electronics, vol. 7, no. 5, pp. 1216-1226, 2014.

[15] C. Schauder and H. Mehta, "Vector analysis and control of advanced static var compensators," Generation, Transmission and Distribution, IEE Proceedings C, vol. 140, no. 4, pp. 299-306, Jul. 1993, ISSN: 0143-7046.

[16] H. Zhou, T. Bhattacharya, D. Tran, T. S. T. Siew, and A. M. Khambadkone, "Composite Energy Storage System Involving Battery and Ultracapacitor With Dynamic Energy Management in Microgrid Applications," IEEE Transactions on Power Electronics, vol. 26, no. 3, pp. 923-930, Mar. 2011, ISSN: 0885-8993.

[17] "Ieee standard for interconnecting distributed resources with electric power systems," IEEE Std 1547-2003, pp. 1-28, Jul. 2003. 